\title{
Factors Affecting Smoking And Predictors Of Academic Achievement Among Primary School Children In Jordan
}

Mariam M. Kawafha, Irbid National University, Jordan

\begin{abstract}
The aim of this research is to assess the relationship among the smoking status of primary school children with demographics and the smoking characteristics of their parents. In addition, to identify any factor( $s$ ) considered strong predictor(s) of academic achievement. A descriptive cross-sectional design was used in this study. A cluster random sample of 453 primary school children was obtained from both genders. Smoking was measured by the self-reported smoking behavior questionnaire and the educational achievement was measured by "Jordan Certificate of Primary Education." The results indicate that there is a significant correlation between smoking status $r_{p b}((451)=-.44, p<.001)$, age of smoking initiation $r((451)=-.30, p<.001)$, daily cigarettes $r((451)=-.12, p<.01)$, and smoked 100 cigarettes in lifetime $r_{p b}((451)=-.28, p<$ $.01)$ with academic achievement. In multiple hierarchical regression analysis, Model 1 explained $12 \%$ of variance with academic achievement. By adding the smoking characteristics Model 2 explained $28 \%$ of the variance with academic achievement. The conclusion is that there is a correlation between smoking and academic achievement.
\end{abstract}

Keywords: Academic Achievement; Children; Jordan; Smoking; Smoking Status; Primary School

\section{INTRODUCTION}

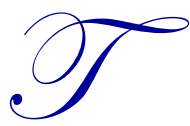

obacco smoking is a threat to the economic development of many societies and a preventable cause of illness and death for millions. 1.8 billion young people, ages 10 to 24, smoke cigarettes (World Health Organization, 2008). Most tobacco-related deaths are in developed countries (World Health Organization, 2008; World Health Organization, 2013). This trend is expected to switch by the year 2030 when $80 \%$ of tobacco-related deaths will be in developing world (World Health Organization, 2008; World Health Organization, 2013). This prediction is based upon declining cigarette consumption in developed countries and rapidly rising consumption in developing countries.

The epidemic and disease burden caused by tobacco using is increasingly evident in Jordan (Shehab, Belbeisi, \& Walke, 2002; Belbeisi, Zindah, Walke, Jarrar, \& Mokdad, 2004; Nsour, Mahfoud, Kanaan, \& Balbeissi, 2008). The estimated number of smokers who die each year from smoking-related diseases in Jordan are as follows: chronic disease accounted for more than 50\% of annually deaths (Jordan Ministry of Health, 2009); heart disease and stroke was responsible for a third of all deaths; malignant neoplasm was responsible for about $13 \%$ of deaths, with lung cancer being the leading cause of cancer death ("Experts Tackle Religious," 2002). Furthermore; tobacco use costs smokers in Jordan 250 million JD each year (Dhavan, Stigler, Perry, Arora, \& Srinathreddy, 2010).

Moreover, smoking affects school achievement of children. Children who have smoked are more likely to: decrease attentiveness, cognitive, and memory functions; have difficulty remembering information and verbal learning impairment (Yale, 2005; Garrett, Dube, Trosclaire, Caraballo, \& Pechacek, 2011); drop out of school (Koivusilta, Rimpel, \& Vikat, 2003; Paavola, Vartiainen, \& Haukkala, 2004; Pennanen, Haukkala, Vries, \& Vartiainen, 2011); have school achievement deterioration over time (Brook, Balka, Rosen, Brook, \& Adams, 2005); and engage in delinquent behavior (Bachman, O’Malley, Schulenberg, Johnston, Freedman-Doan, \& Messersmith, 
2008; Bryant \& Zimmerman, 2002; Tucker, Ellickson, \& Klein, 2003; van den Bree, Whitmer, \& Pickworth, 2004; UNICEF, 2007).

Smoking among Jordanian school students rose from 13\% in 2004 to $20 \%$ in 2007 (Nsour, Mahfoud, Kanaan, \& Balbeissi, 2008). However, there is a scarcity of studies that addressed smoking and academic achievement among Jordanians. In addition, all the data available for smoking among Jordanians were focused on children above the age of 15 years and adults. Therefore, it is essential to assess the relationship among smoking status of primary school children aged 10-12 years with age, sex, family income/month, number of family members, grade level and smoking characteristics (smoking status, age of smoking initiation, daily cigarettes per day, smoker in home, friends who smoke, smoked 100 cigarettes in lifetime). In addition, it aims to identify any factor(s) considered strong predictor(s) of academic achievement that will provide information for policy makers about school children smoking in order to develop school health smoking cessation programs in Jordan.

\section{METHODS}

A quantitative approach using a descriptive correlational cross-sectional design utilizing predictive method was applied to identify any factor(s) considered strong predictor(s) of academic achievement.

\section{Participants}

The population of this study consisted of school aged children attending governmental and private primary schools in Northern Jordan. The sample size was estimated to be at least 345 primary school children, accepting a margin of error not exceeding 5\% with a confidence level of $95 \%$. Sample size calculation was determined based on version 3.0 at two-tail .05 level of significance, power of .80, and small effect size of .05 for regression.

\section{Instruments}

The first part of the tool was demographic data including: age, sex, family income, number of family members, grade level - this section was answered by the child's parents or caregivers. Smoking characteristics (smoker, non smoker, age of smoking initiation, smoker in home, smoked 100 cigarettes in lifetime, friends who smoke, and daily cigarettes) was filled out primary by school children self reporting.

The second part of the tool included the educational achievement of the child and it was evaluated through the values derived from the child's certificate "Jordan Certificate of Primary Education." The raw score of the "Jordan Certificate of Primary Education" consists of grades of all the participants of the curriculum where the schools usually keep a copy of this certificate. Students' records for the last academic year were retrieved and school examination records for one year were as follows: a scale of 90 and above out of 100 meaning excellent, while 80$89 \%$ was very good $70-79 \%=$ good $; 60-69 \%=$ poor, $50-59=$ very poor and less than $50 \%=$ failed.

\section{Ethical Considerations}

This study was approved by the research ethical committees at Irbid National University and Ministry of Education. A letter was sent to the Ministry of Education describing the nature and significance of the study, and requesting permission to have access to students and their records. Official administrators and staff members in the primary schools were informed about the study purposes and permission was requested to conduct the study using the appropriate channels of communication. A letter explaining the study and its purposes was sent to the parents/caregivers in order to obtain a consent form and permission for their children to participate, and requesting mothers/caregivers to answer demographic questionnaire. Furthermore, the parents/caregivers were instructed that their completion of the questionnaire will be considered as written consent for their participation. Students not wishing to participate was asked to return the questionnaire unfilled. The confidentiality and anonymity of the information were assured. Moreover, each student has a number in his/her school so this number was used in coding questionnaires to maintain confidentiality of the data. 


\section{Procedure}

A cluster random sample was obtained from the entire public and private primary schools from both sexes in northern Jordan. A list of public and private primary schools in northern Jordan including children aged from 1012 years old was obtained from the Ministry of Education. In this study the researcher used four-stage cluster sampling. First stage-cluster was the selection of northern Jordan governorate and three governorates were randomly selected. Second stage-cluster was the selection of schools and it was done separately for each gender. Primary school children within each governorate were listed and a sample from the whole school was randomly selected. Third stage was the selection of classrooms from the schools. In this stage, the list of all primary school classrooms in each school were listed on slips of paper and randomly selected. Finally, the fourth stage-cluster was the selection of children by using simple random sampling. All primary school children enrolled in the classroom were listed and randomly selected. A proportional number of students from $4^{\text {th }}, 5^{\text {th }}$, and $6^{\text {th }}$ elementary classes was obtained and completed questionnaires were received: $35.1 \%$ from $4^{\text {th }}$ elementary classes, $30.4 \%$ from $5^{\text {th }}$ elementary classes and $34.5 \%$ from $6^{\text {th }}$ elementary classes. Information about the study along with the study's questionnaire was distributed to students in their classrooms. The questionnaire was kept in envelopes with full instructions and sent home with the children to give to their parents; the questionnaire took approximately 5 minutes to be completed. Parents were asked to retain the completed questionnaires and send them back to school with their children the next day. The researcher was responsible for collecting the completed questionnaires from the children. The researcher asked the teacher to leave classroom and the students were asked to complete questionnaires on the second day and the researcher collected the completed questionnaires. The questionnaire took approximately 15 minutes to be completed. Data related to the student's academic achievement was obtained from "Jordan Certificate of Primary Education." The student's scores mean in the certificate was compared with the mean of the participants in relation to smoking characteristics.

\section{Data Analysis}

Data analyses were conducted using the statistical package of Social Science (SPSS) version 17 computer program. The level of significance established for this study is set at an alpha level of $\leq 0.05$.

\section{Results}

\section{Sample Characteristics}

Seven hundred and fifty questionnaires were distributed to randomly selected classes of primary school children. Four hundred and fifty three completed the questionnaire yielding a $60.4 \%$ response rate. The participants were $53.2 \%$ male and $46.8 \%$ female. Educational level of respondents was: $35.1 \%$ were in $4^{\text {th }}$ elementary classes, $30.4 \%$ were in $5^{\text {th }}$ elementary classes, and $34.5 \%$ were in $6^{\text {th }}$ elementary classes. Most respondents $(97.1 \%)$ reported living in families of more than four persons. Monthly income ranged from 50 Jordanian Dinar (JD) to 4000JD (70\$$5600 \$$ ) with a median of $360 \mathrm{JD}(500 \$)$. The grades of academic achievement regarding this sample range from 5099 with mean 79.8 .

\section{DESCRIPTIVE SMOKING CHARACTERISTICS OF THE STUDY SAMPLE RELATED TO SMOKING}

Most respondents $(56.9 \%)$ had a member of their household who was a smoker. This smoker was generally either a father $(31.6 \%)$ or a brother $(21.8 \%)$. Almost one-third $(33.1 \%)$ of respondents reported that at least some of their friends were smokers. Most students $(77.3 \%)$ had never smoked and $22.7 \%$ were smokers. More than a quarter of smoker $(26.2 \%)$ had smoked at least 100 cigarettes in their lives. Approximately half students $(48.6 \%)$ reported that their daily cigarettes 11 or more, $29.1 \%$ smoke 6-10 cigarettes/day and $22.3 \%$ smoke $1-5$ cigarettes/day. About half smokers $(48.6 \%)$ reported that they had started smoking between ages 11-12, 29.1\% between ages 9-10 and $22.3 \%$ by the age 8 or less (Table 1 ). 
Table 1: Descriptive Smoking Characteristics of the Study Sample Related to Smoking $(N=453)$

\begin{tabular}{lc}
\hline \multicolumn{1}{c}{ Variables } & $\% \mathbf{~ n}$ \\
\hline Smoking Status & \\
Smoker & $22.7 \%(103)$ \\
Non Smoker & $77.3 \%(350)$ \\
Smoker in home & \\
Relative in home & $56.9 \%(258)$ \\
Parent & $31.6 \%(143)$ \\
Sibling & $21.8 \%(99)$ \\
Other & $2.4 \%(11)$ \\
Friends who smoke & \\
All & $5.9 \%(27)$ \\
Most & $5.5 \%(25)$ \\
Some & $33.1 \%(150)$ \\
None & $55.5 \%(251)$ \\
Age of smoking initiation(yrs) & \\
$\leq 8$ & $22.3 \%(23)$ \\
$9-10$ & $29.1 \%(30)$ \\
$11-12$ & $48.6 \%(50)$ \\
Smoked 100 cigarettes in life time & $26.2 \%(27)$ \\
Daily cigarettes & \\
$1-5$ & $22.3 \%(23)$ \\
$6-10$ & $29.1 \%(30)$ \\
$\geq 11$ & $48.6 \%(50)$ \\
\hline
\end{tabular}

\section{THE RELATIONSHIP BETWEEN SMOKING CHARACTERISTICS AND ACADEMIC ACHIEVEMENT}

Results revealed that there were significant and negative correlations between smoking status and academic achievement $\mathrm{r}_{\mathrm{pb}}(451)=-.44, \mathrm{p}<.001$, in which children who usually are not smokers had high scores in academic achievement than children who are smokers (Table 2). Significant and negative correlation was noted between academic achievement and age of smoking initiation $\mathrm{r}(451)=-.40, \mathrm{p}<.001$. Significant correlations at $\mathrm{p} \leq .001$ were found between daily cigarettes and academic achievement $\mathrm{r}(451)=-.12, \mathrm{p}<.01$. Smoked 100 cigarettes in lifetime was significantly related to academic achievement $r_{p b}(451)=-.28, p<.01$. No significant correlation was found between academic achievement and smoker in home and friends who smoke (Table 2). Significant correlation was found between smoking status and monthly income $\mathrm{r}(451)=.39, \mathrm{p}<.001$ (Table 3).

Table 2 :Correlation between Smoking Characteristics and Academic Achievement $(\mathbf{N}=453)$

\begin{tabular}{lc}
\hline \multicolumn{1}{c}{ Smoking Characteristics } & Academic Achievement \\
\hline Smoking status & $-.44^{* *}$ \\
Age of smoking initiation & $-.40^{* *}$ \\
Daily cigarette & $-.12^{*}$ \\
Smoker in home & -.01 \\
Friends who smoke & .09 \\
Smoked 100 cigarettes in lifetime & $-.28^{*}$ \\
\hline$* *$ Correlation is significant at $\mathrm{P}<0.001$ levels (two tailed). * Correlation is \\
significant at $\mathrm{P}<0.01$ levels (two tailed)
\end{tabular}

Table 3: Correlation among Academic Achievement, Smoking Status, and Selected Demographic Variables $(\mathrm{N}=453)$

\begin{tabular}{|c|c|c|c|c|c|c|c|}
\hline & & 1 & 2 & 3 & 4 & 5 & 6 \\
\hline 1 & Academic Achievement & & & & & & \\
\hline 2 & Smoking Status & $-.44 * *$ & & & & & \\
\hline 3 & Age & .07 & $.41 * *$ & & & & \\
\hline 4 & Gender & .022 & .07 & .010 & & & \\
\hline 5 & Monthly Income & $.34 *$ & $.39 *$ & .01 & -.08 & & \\
\hline 6 & Family Number & .09 & -.001 & .06 & -.09 & -.11 & \\
\hline
\end{tabular}




\section{Predictors of Academic Achievement}

The analysis showed that Model 1 (age, sex, family income/month, number of family members, and grade level) explained $12 \%\left(\mathrm{R}^{2}=.12\right)$ of the variance in academic achievement. In this model, family income/month $(\mathrm{b}=$ $5.60, \mathrm{p}<.001)$ was highly significant and a positive predictor of academic achievement among primary school children. This indicated that there were positive associations between incomes and academic achievement indicating that children who reported higher level of income are more likely to report a higher score on academic achievement (Table 4). On the other hand, age, sex, number of family member and grade level were not significant predictors of academic achievement.

Table 4: Two-Step Multiple Hierarchical Regression to Examine the Most Significant Predictors of Academic Achievement in Selected Demographics and Smoking Characteristics (N = 453)

\begin{tabular}{|c|c|c|c|c|}
\hline \multirow[b]{2}{*}{ Variables } & \multicolumn{2}{|c|}{ Model 1} & \multicolumn{2}{|c|}{ Model 2} \\
\hline & B & P-Value & B & P-Value \\
\hline Sex & 1.4 & .21 & .63 & .56 \\
\hline Age & .52 & .08 & .21 & .5 \\
\hline Income & .01 & $<.001$ & .01 & $<.001$ \\
\hline Grade level & .52 & .08 & .21 & .5 \\
\hline Number of family members & -.17 & .53 & -.15 & .57 \\
\hline Age of smoking initiation & & & -3.2 & $<.001$ \\
\hline Smoker & & & -4.3 & $<.001$ \\
\hline Non smoker & & & 2.1 & .26 \\
\hline Smoker in home & & & -2.5 & .36 \\
\hline Friends who smoke & & & -2.1 & .22 \\
\hline Smoked 100 cigarettes in lifetime & & & -2.4 & $<.001$ \\
\hline Daily cigarettes & & & -.74 & $<.01$ \\
\hline Model & $\mathbf{R}^{2}$ & Adjusted $\mathbf{R}^{2}$ & $\mathbf{R}^{2}$ change & P-Value \\
\hline Model 1 & .12 & .14 & - & $<.001$ \\
\hline Model 2 & .28 & .21 & .16 & $<.001$ \\
\hline
\end{tabular}

In Model 2, by adding the smoking characteristics, the model explained $28 \%$ of the academic achievement $\left(\mathrm{R}^{2}=.28\right)$. That is, smoking characteristics significantly increased the prediction of academic achievement $(16 \%)$ beyond the demographics $\left(\mathrm{R}^{2}\right.$ change $\left.=.16\right)$. The significant predictors in Model 1 remained significant in Model 2.

The significant negative predictors in Model 2 were: age of smoking initiation $(b=-3.2, p<.001)$, smoker $(b=-4.3, p<.001)$, smoked 100 cigarettes in lifetime $(b=-2.4, p<.001)$, and daily cigarettes $(b=-.74, p<.001)$. This indicated that the negative sign for the slope for smoked, smoking initiation, daily cigarettes, and smoked 100 cigarettes in lifetime predicted a lower score in academic achievement. The predictive relation of smoker to academic achievement was signifying that with a decrease in the number of cigarettes predicted a higher academic achievement. The other three smoking characteristics variables (non smoker, smoker in home, and friends who smoke) have no significant association to academic achievement when other predictors were statistically controlled. Overall, academic achievement was highly predictable from this set of predictors; the strongest unique predictive contributions were from smoker followed by age of smoking, smoked 100 cigarettes in lifetime, and daily cigarettes. Neither non smoker, smoker in home nor friends who smoke was found to be significantly predictive of academic achievement in this regression.

\section{DISCUSSION}

The results showed that smoking has a specific effect on a child's academic achievement. Children who are non smokers reported higher academic achievement. This result is consistent with the finding of Yale's study conducted in 2005 (Yale, 2005). Yale (2005) compared school student daily smokers with non-smokers and found that those who smoked tobacco experienced impaired cognitive functions, inattentiveness and distractibility, influence memory, difficulty manipulating information, and school achievement. Children who smoked had easily lost information from their minds and manipulated information with difficulty. They also found impairment with verbal learning and with the ability to pay attention (Yale, 2005). Similar results were found in the study conducted 
by The Northwest Ohio Youth Tobacco Survey in 2003. The study showed that 24 percent of students with excellent grades and 55 percent of students with poor grades reported ever being smokers (Department of Health, 2002). The significance value revealed that the likelihood of ever being smokers was 3.02 times greater for failing grade students than for excellent grade students (Khuder, Price, Jordan, Khuder, \& Silvestri, 2008). Other studies found that students who smoke more do unsuccessfully at school compared with others; in addition, development in the smoking uptake continuum influenced the worsening of school achievement over time (Pennanen, Haukkala, Vries, \& Vartiainen, 2011). Likewise, Martínez-Mantilla and his colleagues (2008) found that daily cigarette smoking was associated with poor academic achievement (Martinez-Mantilla, Amaya-Naranjo, Campillo, Diaz-Martinez, \& Campo-Arias, 2008).

Smoking initiation was significantly correlated with academic achievement. Smoking initiation was correlated with failing grades. This finding is consistent with a number of different studies in the literature (Khuder, Price, Jordan, Khuder, \& Silvestri, 2008; Warburton, Wesnes, \& Revell, 1984; Coogan, Adams, Geller, Brooks, Miller, Lew, \& Koh, 1998) in which they found academic achievement at school was correlated with earlier age at onset of smoking. Students who initiate smoking earlier failed or achieved low grades than other students with higher grades. Likewise; Doku and his colleagues (2010) found that students who had poorer scores than the average school achievement smoked 5.4 times greater than students with much better than average school achievement (Doku, Koivusilta, Rainio, \& Rimpela, 2010).

Income is another significant factor. It was found that in the current study, high family income was associated with good academic achievement and smoking among children. This result differs from Laaksonen and his colleagues (2005) who found that those with low income more often smoke than those with higher incomes (Laaksonen, Rahkonen, Karvonen, \& Lahelma, 2005). This finding may be understood in terms of justification for children who are much more likely to smoke if they are surrounded by attractive tobacco advertising, such that if their sport is sponsored by a Tobacco Company or if their film idols smoke in movies. The children with high family income are more likely to afford cigarettes than children with low income. Smoking costs approximately 60 JD (85\$) monthly, which would be expensive for students from a family struggling and concerned about not wasting money.

In the current study, the results showed that having a friend who smoked and a smoker at home correlated non-significantly with academic achievement. In contrast, to other studies by Khuder and his colleagues (2008), they found a negative significant value between academic achievement and smoker in home and close friends who smoke (Khuder, Price, Jordan, Khuder, \& Silvestri, 2008). Moreover, de Vries, Backbier, Kok, and Dijkstra (1995) found that students who have more people in their environment who smoke have low academic achievement (de Vries, Backbier, Kok, \& Dijkstra, 1995). This result is possibly due to students who are more liable to outside influence that persuades the start and progression of smoking (Mathur, Stigler, Perry, Arora, \& Reddy, 2008). Children may try smoking to cope with a social stressor and the stresses of growing up. Also environmental factors such as price, availability, advertising/media, and public smoke have a relation to initiation of child smoking (World Health Organization, 2000).

\section{CONCLUSIONS AND RECOMMENDATIONS}

In this study, we concluded that smoking has an association with academic achievement. The consequence of this problem includes: smoking leads to affect children's physical and mental development and reduces academic achievement. Therefore, smoking can be considered a barrier to optimal learning. However, given the weak receptiveness of children toward anti-smoking information of any sort, policy makers must restrict the availability of tobacco products to children. Jordan does not have a law prohibiting the sale of cigarettes to minors; although it does have a non-enforced law that limits cigarette sales to only licensed businesses. The Jordan Ministry of Education has rules against smoking by staff and students on school premises, however, these rules are not enforced. Governments can do more than fight the smoking epidemic with laws. Anti-smoking media campaigns sponsored by governments are an active approach reinforcing the message that cigarettes are harmful. Therefore, nurses should consider smoking prevention as a social behavior that is highly reinforced by friends, family, and habit. Finally, a community support of smoking prevention and cessation program along with effective strategies may help overcome this problem. 


\section{AUTHOR INFORMATION}

Mariam M. Kawafha, Ph.D., Assistant Professor, Dean of Faculty of Nursing, Irbid National University, Irbid, Jordan. Tel: +962 2 776201945; Fax: +962 2 7056681. E-mail: mariamsltn204@ gmail.com

\section{REFERENCES}

1. Bachman, J. G., O’Malley, P. M., Schulenberg, J. E., Johnston, L. D., Freedman-Doan, P., \& Messersmith, E. E. (2008). The education-drug use connection: How successes and failures in school relate to adolescent smoking, drinking, drug use, and delinquency. Mahwah, NJ: Erlbaum.

2. Belbeisi, A., Zindah, M., Walke, H., Jarrar, B., \& Mokdad, A. H. (2004). Assessing risk factors for chronic disease--Jordan. MMWR Morb Mortal Wkly Rep 2006, 55, 653-655.

3. Brook, J. S., Balka, E. B., Rosen, Z., Brook, D. W., \& Adams, R. (2005). Tobacco use in adolescence: Longitudinal links to later problem behavior among African American and Puerto Rican urban young adults. Journal of Genetic Psychology, 166(2), 133-151.

4. Bryant, A. L., \& Zimmerman, M. A. (2002). Examining the effects of academic beliefs and behaviors on changes in substance use among adolescents. Journal of Educational Psychology, 94(3), 621-637.

5. Coogan, P. F., Adams, M., Geller, A. C., Brooks, D., Miller, D. R., Lew, R. A., Koh, H. K. (1998). Factors associated with smoking among children and adolescents in Connecticut. Am. J. Prev. Med, 15, 17-24.

6. Department of Health (2002). OSPI, Department of Social and Health Services and Office of Community Development. Smoking and Academic Performance in the State of Washington. Nation Journal, 5(6).

7. de Vries, H., Backbier, E., Kok, G., \& Dijkstra, M. (1995). The impact ofsocial influence in the context of attitude, self-efficacy, intention, and previous behavior as predictor of smoking onset. J Appl Soc Psychol., 25(3), 237-57.

8. Dhavan, P., Stigler, M. H., Perry, C. L., Arora, M., \& Srinathreddy, K. (2010). Tobacco use associated with academic failure among government school students in urban India. Journal of School Health, 80(11).

9. Doku, D., Koivusilta, L., Rainio, S., \& Rimpela, A. (2010). Socioeconomic differences in smoking among Finnish adolescents from 1977 to 2007. The Journal of Adolescent Health: Official Publication of the Society for Adolescent Medicine, 47(5), 479-487.

10. Experts tackle religious, health issues on smoking. (2002). The Jordan Times.

11. Garrett, B. E., Dube, S. R., Trosclair, A., Caraballo, R. S., \& Pechacek, T. F. (2011). Cigarette smoking United States, 1965-2008, National Center for Chronic Disease Prevention and Health Promotion. CDC. 60(01), 109-113.

12. Jordan Ministry of Health (2009). Directorate of information and research: Mortality data in Jordan, 2006. Information and Research Newsletter, 1, 1-4.

13. Koivusilta, L., Rimpel, A., \& Vikat, A. (2003). Health behaviours and health in adolescence as predictors of educational level in adulthood: A follow-up study from Finland. Social Science and Medicine, 57, 577593.

14. Khuder, S. A., Price, J. H., Jordan, T., Khuder, S. S., \& Silvestri, K. (2008). Cigarette smoking among adolescents in Northwest Ohio: Correlates of prevalence and age at onset. International Journal of Environmental Research and Public Health, 5(4), 278-289.

15. Laaksonen, M., Rahkonen, O., Karvonen, S., \& Lahelma, E. (2005). Socioeconomic status and smoking: Analysing inequalities with multiple indicators. European Journal of Public Health, 15(3), 262-269.

16. Martínez-Mantilla, J. A., Amaya-Naranjo, W., Campillo, H. A., Díaz-Martínez, L. A., \& Campo-Arias A. (2008). Daily cigarette smoking among Colomian High School students: Gender related psychosocial factors. Rev Latino-am Enfermagem 2008 setembro-outubro, 16(5), 903-7.

17. Mathur, C., Stigler, M., Perry, C., Arora, M., \& Reddy, S. (2008). Difference in prevalence of tobacco use among Indian urban youth: the role of socioeconomic status. Nicotine Tob Res., 10(1), 109-16.

18. Nsour, M., Mahfoud, Z., Kanaan, M. N., Balbeissi, A. (2008). Prevalence and predictors of non-fatal myocardial infarction in Jordan. Eastern Mediterranean Health J, 14, 818-830.

19. Paavola, M., Vartiainen, E., \& Haukkala, A. (2004). Smoking from adolescence to adulthood: The effects of parental and own socioeconomic status. European Journal of Public Health, 14(4), 417-421. 
20. Pennanen, M., Haukkala, A., Vries H., \& Vartiainen, E. (2011). Longitudinal study of relations between school achievement and smoking behavior among secondary school students in Finland: Results of the ESFA study. Substance Use \& Misuse, 46, 569-579.

21. Shehab, F., Belbeisi, A., \& Walke, H. (2002). Prevalence of selected risk factors for chronic diseaseJordan. MMWR Morb Mortal Wkly Rep 2003, 52, 1042-1044.

22. Tucker, J. S., Ellickson, P. L., \& Klein, D. J. (2003). Predictors of the transition to regular smoking during adolescence and young adulthood. Journal of Adolescent Health, 32(4), 314-324.

23. UNICEF (2007). United Nations Children's Fund. Child nutrition: Jordan Country profile US Department of Health and Human Services, Office of the Surgeon General The Surgeon General's Call to Action to Prevent and Decrease Overweight and Obesity, (2001), Retrieved May 15, 2002 from http://www.surgeongeneral.gov/topics/obesity/

24. van den Bree, M. B. M., Whitmer, M. D., \& Pickworth, W. B. (2004). Predictors of smoking development in a population-based sample of adolescents: A prospective study. Journal of Adolescent Health, 35(3), 172-181.

25. Warburton, D. M., Wesnes, K., \& Revell, A. (1984). Smoking and academic performance. Current Psychology, 3(3), 25-31.

26. World Health Organization (2000). World Health Report. Geneva: Author. Wu, LT, Anthony JC (1999a) Tobacco smoking and depressed mood in late childhood and early adolescence. American Journal of Public Health, 89(12), 1837-1840.

27. World Health Organization (2008). WHO report on the global tobacco epidemic, 2008: The MPOWER package. Geneva, Switzerland: WHO Press.

28. World Health Organization (2013). Media centre; Fact sheet $N^{\circ} 339$. Retrieved 6 June 2013 from http://www.who.int/mediacentre/factsheets/fs339/en/index.html

29. Yale, A. (2005). Smoking causes memory and cognitive impairment in adolescents. Biological Psychiatry, 57, 56-66. 